\title{
APONTAMENTOS SOBRE O COMUM EM PORTUGAL E NO BRASIL
}

\author{
Beatriz Nascimento Ko Fontenele ${ }^{1}$ \\ Isabella Flach Gomes ${ }^{2}$
}

DOI: 10.5752/P.2316-1752.2019v26n39p221

\section{Resumo}

Novas teorias sobre o comum têm sido formuladas com o intuito de se pensar uma alternativa ao binômio público-privado em algumas urbes do mundo. Todavia, parece irresponsável pensar que tal prática política acomete de maneira homogênea o Norte e o Sul global. Frente a isso, este estudo apresenta uma breve introdução acerca das teorias dos comuns urbanos, colocadas em prática por meio das okupas, e uma comparação entre essas manifestações em Portugal e no Brasil, levando o estudo, ainda, a traçar um paralelo com a teoria decolonial - sem a pretensão de esgotar o assunto do comum.

Palavras-chave: Comum. Okupas. Portugal-Brasil; Decolonial.

\footnotetext{
1. Arquiteta e Urbanista pela Universidade Federal do Ceará, mestranda em Planeamento e Projecto Urbano pela Universidade do Porto. E-mail: bkfontenele@gmail.com

2. Arquiteta pela Universidade Federal de Minas Gerais, especialista em Memória e Historiografia pela PUC Minas, mestranda em Arquitetura e Urbanismo pela Universidade Federal de Minas Gerais. E-mail: isabellaflach@gmail.com
} 
NOTES ON THE COMMON IN PORTUGAL AND BRAZIL

\begin{abstract}
New theories about the commons have been formulated in order to create an alternative to the public-private binomial in some cities around the world. However, it would be irresponsible to think that such political practice homogeneously affects the North and South. In light of this, this study presents a brief introduction about the urban commons, put into practice through the okupas, and a comparison between these manifestations in Portugal and in Brazil, leading the study to draw a parallel with the decolonial theory - with no intentions to cease the subject of the commons.
\end{abstract}

Keywords: Commons. Okupas. Portugal-Brazil. Decolonial.
NOTAS SOBRE LO COMÚN EN PORTUGAL Y BRASIL

\section{Resumen}

Se han formulado nuevas teorías sobre lo común para pensar en una alternativa al binomio públicoprivado en algunas ciudades del mundo. Sin embargo, sería irresponsable pensar que dicha práctica política afecta de manera homogénea al Norte y al Sur globales. En vista de esto, este estudio presenta una breve introducción sobre las teorías de los comunes urbanos, puestas en práctica por medio de las okupas y una comparación entre estas manifestaciones en Portugal y Brasil, lo que lleva al estudio a establecer un paralelismo con la teoría decolonial, sin pretender agotar el tema de lo común.

Palabras-claves: Común. Okupas. Portugal-Brasil. Descolonial. 


\section{Introdução}

Uma palavra pode apreender vários significados com o passar do tempo, desaparecer ou ser resgatada, às vezes até com outros sentidos. O uso do vocábulo comum compreende uma parte da história mundial, uma vez que remonta às terras comunais da Idade Média. Com uma conotação diferente da anterior, o comum atual ainda persiste, tanto na teoria quanto na prática, como uma palavra-conceito que pode ser entendida como peça importante do vocabulário. Partindo inicialmente de uma abordagem ligada a recursos compartilhados até uma concepção como realidade prática, o termo passou a retratar a transição de uma visão econômica ortodoxa para uma perspectiva revolucionária atual, quando modelos de gestão alternativos ao binômio público/privado fazem-se urgentes, tomando distância do socialismo de Estado e do capitalismo de mercado, de forma a abrir, por conseguinte, uma terceira via de lógica política. De saída, é importante ressaltar que não é pressuposto deste texto apresentar uma ontologia do comum e, sim, contextualizá-lo brevemente pelas reformulações de sentido, para então pensar o comum atual e suas diferentes formas de manifestação em Portugal e no Brasil.

A ideia do comum como se conhece hoje começou a ser formulada em meados da década de 1960 e até a contemporaneidade passou por ressignificações de diversos autores (HARDIN, 1968; OSTROM, 1990; HARDT e 
NEGRI, 2009; DARDOT e LAVAL, 2017). O entendimento acerca do termo foi alterado desde o início de sua formulação, ao passo que evoluíram as dinâmicas neoliberais e os arranjos de mercado nas sociedades contemporâneas foram fortalecidos. Essas ressignificações embasaram análises de experiências práticas, cujo palco era e é a cidade - ou as cidades - e, portanto, de caráter dinâmico e heterogêneo, como reflexo de tensões sociais, culturais, econômicas e políticas inerentes aos processos de transformação urbana em diferentes partes do globo.

Para tanto, a primeira seção do artigo busca apresentar um breve percurso do comum, relativo aos diferentes sentidos atribuídos à palavra pelos principais pensadores europeus. Já na segunda parte, o texto volta-se para o comum urbano, investigando as ocupações e as okupas - as primeiras, que reivindicam o direito à moradia digna e a segunda, de caráter anárquico, que luta pelo fim das relações de posse e da propriedade privada - como manifestações coerentes com o sentido do termo. Apesar de serem distintas, tanto as ocupações quanto as okupas baseiam-se em fundamentos do comum, significando que tais práticas políticas e relações sociais estão para além do capital, como ocorre em cozinhas comuns, creches, hortas comunitárias e nas próprias ocupações de terras.

Sendo o exercício de investigação um processo, este texto percorre um caminho exploratório que se inicia com uma revisão bibliográfica de autores europeus relevantes 
para a temática dos comuns urbanos. Entretanto, parece errado imaginar que essa prática política tenha atingido de maneira homogênea as periferias e as metrópoles mundiais. Assim, uma análise comparativa entre o movimento okupa no Brasil e em Portugal, "colônia" e "metrópole", foi proposta, sendo essas elucubrações possíveis pelo fato de uma das autoras morar em terras lusitanas. A complexidade de agentes, forças e incoerências identificadas em ambos os contextos, devido às diferenças históricas, trazem à luz a necessidade de cautela quanto à aplicabilidade do próprio termo.

Diante disso, o texto apresenta a perspectiva portuguesa (LEITÃO, 2016; MOURA, 2017; LÓPEZ, 2017) - ciente da carência de estudos sobre o movimento - e a brasileira (MAYER, 2015; TONUCCI FILHO, 2017; CAMPOS e LÓPEZ, 2020) quanto às ocupações e okupas, com o intuito de entender como o fator da colonização influenciou as diferentes abordagens desses comuns urbanos. Ao trazer à tona a realidade brasileira, torna-se inevitável a inserção da abordagem decolonial, a fim de explorar também os próprios limites do pensamento comum.

Este texto não possui a pretensão de esgotar o assunto, mas pensar as formulações do comum até o presente, enfrentar incoerências e experimentar caminhos de pensamento. Novas condutas devem ser incorporadas no cotidiano das pessoas de modo a suprir os efeitos negativos do sistema capitalista e a transformar a realidade, 
para que os sujeitos possam vislumbrar outros futuros possíveis e espaços mais democráticos para a prosperidade da vida.

\section{Os comuns, um breve percurso}

O interesse em estudar o comum surge em um cenário de ressignificação desse conceito. Na Idade Média europeia, o termo referia-se às parcelas de terras que eram entregues aos camponeses com o intuito de conter possíveis insurgências. Federici (2017) explica que essas terras sofreram com os cercamentos e o desmonte das experiências comuns de maneira similar às terras das colônias na transição para o sistema colonial-capitalista.

Nessa virada, outros processos foram adicionados, tais como "as políticas mercantilistas, o colonialismo, o tráfico de escravos, o metalismo e o protecionismo, a legislação disciplinadora do trabalho nas fábricas, a montagem da dívida pública, e a expansão do crédito e das finanças internacionais" (TONUCCI FILHO, 2017, p. 48-49).

No século $X X$, uma retomada significativa do termo comum ocorreu no calor dos levantes populares da década de 1960, quando Hardin (1968), no artigo "The tragedy of the commons", postulou que o livre acesso a recursos finitos por meio de práticas de gestão dos bens comuns, sem controle público ou privado, tenderia a uma natural superexploração e consequente extinção dos recursos, uma vez que os indivíduos competiriam entre si em prol 
de suas próprias vantagens. Apesar de originalmente se referir a recursos naturais, a transposição de tal "tragédia" ao cotidiano indicou que formas de competição e extinção poderiam emergir em uma experiência de microescala do comum, oferecendo fundamento, ainda hoje, para a defesa da propriedade privada e para discriminações por parte da direita mundial.

Apesar do teor negativo da obra supracitada, é importante considerar que as relações de gestão dos comuns na microescala persistiram com o passar do tempo. 0 interesse em estudá-las como bases teóricas data dos anos 1990, principalmente quando Ostrom (1990) revisitou a obra de Hardin, afirmando que a tragédia dos comuns só ocorreria caso não houvesse cooperação entre os envolvidos ou se a comunicação fosse proibida ou ifrelevante. A autora ganhadora do prêmio Nobel de economia construiu sua tese a partir de estudos matemáticos que transformaram prática em teoria, avaliando que os melhores cenários seriam obtidos por meio da divisão igualitária dos bens comuns, em cooperação, auto-organização e autogovernança.

A abordagem mais atual dos comuns surge como resultado da intensa busca por modelos alternativos às duas únicas possibilidades de gestão identificadas na realidade contemporânea neoliberal, a pública e a privada (DE ANGELIS, 2016). Hardt e Negri (2009, p. ix - tradução nossa) utilizam o termo pela primeira vez como uma "alternativa 
política igualmente perniciosa entre o capitalismo e o socialismo" à forma de gerenciamento vigente dos recursos naturais e humanos das cidades, baseada no conceito de comunidade.

Hardt e Negri (2009) foram os primeiros a se referirem aos comuns não como experiências práticas, mas, sim, como um princípio político, o comum - no singular. De acordo com os autores, o comum contemporâneo embasa experiências de produção e reprodução que sejam autônomas, democráticas e autogeridas a caminho de um futuro não capitalista, sem recurso ao comunismo burocrático de Estado (HARDT e NEGRI, 2009). Segundo Dardot e Laval (2017), entretanto, para além de ser uma ferramenta questionadora do papel do Estado como defensor da população contra o mercado, uma vez que a máquina estatal segue construindo um protagonismo neoliberal, o comum firma-se, ainda, como um princípio de ação que deve emergir de movimentos sociais de resistência à neoliberação das sociedades contemporâneas.

Nesse sentido, o termo passa a tratar muito mais do gerenciamento comunitário de um bem do que propriamente o bem em si, tornando o comum um sinônimo para atividades compartilhadas de corresponsabilidade, reciprocidade, solidariedade e democracia. Promove, portanto, um terceiro caminho (prático e político) entre o capitalismo de mercado e o comunismo burocrático de Estado, do patrimônio comum, contrário aos processos 
de cercamento e da propriedade privada (DARDOT e LAVAL, 2017).

Enquanto o público inscreve o que é próprio de todos os sujeitos (algo como uma propriedade privada coletiva, assim, não podendo ser contraposta à propriedade privada), o comum é desprovido desse sentido de propriedade, ou seja, quando o Estado é detentor da coisa pública, possui o poder da exclusão, já que não se trata de um bem comum. Adverso às amarras do binômio público e privado, o comum se destaca, quando além de uma prática (o fazercomum), como um recurso de gestão coletiva, de acesso igualitário, em interdependência com a comunidade, escreve Tonucci Filho (2017).

Na prática comum há um esforço político de transformar todas as áreas públicas em comuns, reintegrando à sociedade sua capacidade de intervir no espaço, sem uma apropriação ligada à posse ou propriedade. Tonucci Filho (2017, p. 36) afirma que "os sujeitos de uma comunidade (communitas) são definidos não por terem uma propriedade ou uma possessão em comum, mas por compartilharem obrigações recíprocas, unidas que estão por um débito, um ônus mútuo", qualificando práticas e ações. Em resumo, o comum representa os recursos e bens "que são produzidos e apropriados coletivamente por uma dada comunidade por meio de práticas e relações de compartilhamento e reciprocidade, fora do âmbito do Estado e do mercado e dos seus respectivos regimes de 
propriedade: público e privado" (TONUCCI FILHO, 2017, p.37-38).

Em concordância, Dardot e Laval (2017) defendem que o termo comum não representa um retorno à ideia comunista eterna (e ao comunismo de Estado), mas uma nova forma de se contestar o capitalismo e de pensar sua superação. Apesar de utilizarem parte do livro para entender como o comum aparecia nas diferentes formas de comunismo, para os autores, o Estado foi responsável por destruir a experiência socialista ao tornar-se proprietário dos meios de produção e da administração pública, significando, além disso, que a suposta execução do comum pelo Estado, na verdade, repercutiu na destruição do comum pelo monopólio estatal.

Baseando-se em Dardot e Laval ${ }^{3}$, Tonucci Filho (2017) levanta um ponto importante, o de que a hibridização do Estado-mercado seria responsável por cessar a oposição frontal do público ao privado, mesclando os dois. Fora disso, o comum incide como uma prática de gestão de recursos compartilhados por um coletivo, deixando de lado o intervencionismo, o monopólio estatal e a valorização de um ideário de propriedade privada. Em um compilado de prospecções ${ }^{4}$, Tonucci Filho (2017) afirma que o pro-

3. Tonucci consultou o texto "Propriedade, apropriação social e instituição do comum", de Pierre Dardot e Christian Laval, publicado em Tempo social (2015).

4. Para tal conjunto de ideias, Tonucci consultou o Manifesto Comunista (2010 [1848]), escrito por Marx e Engels e The idea of communism (2010), editados por Douzina e Zizek. 
jeto comunista se valeu do comum como possibilidade de superação capitalista, sem o intermédio do Estado experimentado no socialismo e sem a propriedade privada da sociedade burguesa, segundo o qual a comunidade se organizava a partir de princípios da autogestão e autogoverno.

A despeito da circunstância da precariedade neoliberal, o artigo "Feminism and the Politics of the Commons in an Era of Primitive Accumulation" (2010), de Silvia Federici, apresenta um estudo das práticas do comum que contraria a sensação de que a lógica do capital estaria completamente introjetada em todas as partes do mundo. Como exemplos, ela aponta as hortas comunitárias urbanas e o processo de "rururbanização", iniciativas de comunidades de imigrantes em sua maioria; a utilização de terrenos baldios por mulheres africanas para a produção de mandioca e de outros produtos da terra nos anos 1990; a replantação de árvores em áreas degradadas, conservação das águas e bloqueio do extrativismo mineral por parte de mulheres latino americanas, filipinas e indianas, em uma luta pela preservação do meio ambiente.

Esse entendimento do comum, entretanto, envolve um “(...) vasto conjunto de conhecimentos, afetos e relações sociais que são externos ao capital, mas que o capital se 
apropria" (HARDT; NEGRI apud ENRIGHT; ROSSI, 2018, p. 37 - tradução nossa) ${ }^{5}$. Essa apropriação pode ocorrer tanto pela prática esvaziada do sentido do comum, quanto pela cooptação do sentido oco, como em frases de efeito e palavras-chave. Seria, como Aschoff (2015) afirma, uma nova geração de narrativas que propõem a solução de problemas da sociedade através da mesma lógica da acumulação e exploração. Algumas dessas manifestações perdem a função ideológica original dos comuns, sendo cooptadas pelas instituições do capital e vendidas por meio de narrativas de solução dos problemas vigentes através exatamente da própria lógica de acumulação capitalista. Essa contradição, encontrada nos denominados new prophets of capital (ASCHOFF, 2015), tem se popularizado por meio dos co-livings e coworkings em prol de "novas" formas de viver.

\section{O comum urbano: ocupações e okupas}

Em oposição aos co-livings dos new prophets of capital, as okupas são exemplos possíveis do comum no contexto urbano. Enright e Rossi (2018) afirmaram que uma relação estrita entre os comuns e o espaço urbano na Europa foi constituída após a crise de 2008, com a latência do mercado financeirizado e a massiva privatização dos territórios. O que se presencia nas cidades globais

5. No original: "the vast array of knowledge, affects and social relations that are external to capital but that capital appropriates." 
atualmente é um processo de empreendedorismo e de restrição dos bens coletivos, como carência de educação, de saúde e de abastecimento de água, especialmente no contexto vigente de austeridade.

Durante a fase de Bem-Estar Social de alguns países do Norte global, a ampliação dos direitos dos cidadãos europeus acompanhou uma crescente exploração sofrida pelos trabalhadores periféricos, mais especificamente do Sul. Devido ao alastramento do neoliberalismo, principalmente a partir de 2008, pode-se dizer que houve uma quebra nas barreiras dos Estados-Nação, disseminando a precarização no globo como um todo (CHAUÍ, 2012). Como resultado da ação neoliberal, o espaço público passou por um encolhimento em detrimento do espaço privado, como se nota por meio das privatizações do transporte, da habitação e da retirada de direitos trabaIhistas chancelada pelos Estados.

Seguindo a lógica da precarização constante, Butler (2018) sugere que o neoliberalismo instaurou a premissa de que há populações descartáveis. Frente a isso, os corpos reunidos em assembleia ${ }^{6}$ recusam-se a receber tal tratamento: "nós não somos descartáveis" (BUTLER, 2018, p. 15). Destaca-se a importância que as relações de cooperação exercem nas economias urbanas, visto que

6. Butler (2018) apresenta o raciocínio que, frente a políticas de austeridade e de precariedade, os sujeitos se reúnem em assembleias - em uma conjunção de corpos diversos - e performam a reivindicação de direitos. 
uma série de experimentos colaborativos baseados no ideal de comunidade, de gerenciamento comunitário e de copropriedade têm se manifestado, como em cooperativas habitacionais, redes cidadãs e grupos solidários. São práticas políticas e relações sociais que estão para além do capital, como ocorre em cozinhas comuns, creches, hortas comunitárias e nas próprias ocupações de terras. Esses exemplos propõem novas formas de socializar, habitar, trabalhar e se alimentar.

No caso da habitação no espaço urbano, as ocupações e as okupas são estratégias de lutas organizadas em que se localizam as práticas comuns. De saída, a escolha da palavra ocupação não é trivial: como Lima (2012) explica, diverso ao sentido de invadir, que sugere a dominância de alguns sobre o território ocupado, o termo ocupar significa aproveitar algum espaço ao estar presente nele. Tanto as ocupações quando as okupas são iniciativas contemporâneas coerentes com os preceitos dos comuns urbanos de resistência a práticas neoliberais e de luta pelos direitos à cidade. Já a diferença entre ocupação com " $\mathrm{C}$ " e com " $\mathrm{K}$ " instala-se no questionamento do modo de viver que é calcado na propriedade privada (LIMA, 2012).

As ocupações urbanas são tomadas como uma conquista de um espaço para vida, uma moradia digna de posse, com infraestrutura e serviços - geralmente é nesse último que o comum se enquadra, nas hortas, creches e cozinhas comunitárias. Por outro lado, as okupas são 
movimentos político-sociais que, para além de serem uma demanda por habitação, são uma alternativa à forma institucionalizada de viver (CAMINHA, 2018), alinhadas à corrente anarquista, que instauram outras formas de morar e gerenciar coletivamente os bens. Como escreve Rudy (2011), o movimento okupa ${ }^{7}$ nasceu da tradução do squatter da Europa, em meio à contracultura, em Nova lorque e Londres, inicialmente representados por hippies, ex-presidiários, desempregados e anarquistas. As okupas, portanto, eram e ainda são baseadas no ideal de comunidade, de gerenciamento comunitário e de copropriedade e exemplificam a prática radical do comum pelo desejo do autogoverno e do questionamento à propriedade privada.

Chauí (2012) explica que, diferentemente de um fim liberal, cujo cerne seria o regime da lei e a garantia das liberdades individuais, a democracia é caracterizada pela criação de direitos. E por direitos, tem-se algo válido para todos os indivíduos, ou seja, é uma condição diferente da carência, da necessidade e do interesse. A filósofa esclarece: enquanto a falta de moradia se enquadra como uma carência, ela retrata algo mais profundo, que seria a recusa do direito à vida digna. Assim, carências, necessidades e interesses diversos manifestam direitos pelos

7. A tradução do termo, utilizado principalmente na Espanha e em Portugal, enfatiza a necessidade de cautela quanto à sua generalização e aplicabilidade dentro do próprio continente europeu. 
quais os sujeitos lutam. Até mesmo conceitos abstratos, como a igualdade, quando encontram a declaração de seus direitos, abrem o campo para a criação de um alargamento dessas palavras. Avançando nesse pensamento, a declaração do direito ao espaço da vida amplia o próprio conceito de espaço - uma moradia que se funda na propriedade privada passa a abarcar outras formas de morar, por exemplo, no caso das okupas.

No tocante à experiência urbana e entendidos pela circunscrição colonial, Brasil e Portugal apresentam muitas distinções. A distância Brasil-Portugal está inscrita inclusive no trato com a palavra baldio - a tradução lusitana remete ao sentido de commons do inglês (TONUCCI FILHO, 2017), enquanto que para o entendimento brasileiro, baldio significa agreste, infrutífero. Porém, a diferença de tratamento quanto às ocupações e okupas nos dois países se estende para além de uma questão de significado de palavras, sendo ativa na maneira como as práticas ocorrem em ambos países.

\section{Ocupações e okupas em Portugal, um breve apanhado}

Os movimentos sociais de forma geral marcaram de maneira expressiva a realidade portuguesa entre os anos 1960 e 1980, devido, mais especificamente, ao golpe de Estado e ao processo revolucionário que o sucedeu, 
culminando na aprovação da Constituição da República Portuguesa, em abril de 1976 (GASPAR, 1990). O "movimento social mais amplo e profundo da história europeia do pós-guerra" (AUGUSTO 2013 apud SANTOS 1984, s.p.) envolveu uma composição de classe complexa formada pelo operariado rural e urbano e pela pequena burguesia assalariada, cujo poder reivindicativo focava, dentre diversas áreas da vida social, a habitação urbana e os novos modos de vida (AUGUSTO, 2013).

O contexto de desenvolvimento industrial e democratização tardios em que o país estava inserido e a consequente migração do campo para a cidade em paralelo à emigração de um milhão e meio de pessoas, sobretudo para a Europa Central, moldou o cenário de ocupações de casas devolutas em Portugal. Como Varela e Alcântara (2016) explicam, outro fator de agravamento foi o aumento da renda do solo pela captura privada de maisvalia associada à transformação do solo em urbanizável, elevando o preço das habitações.

A entrada do país na União Europeia e a consequente mudança de foco das questões internas para problemas comuns ao continente, resultantes sobretudo da globalização (AUGUSTO 2013 apud SANTOS 1984), deu cabo ao debate político em torno das okupações, incorporado às conversas sobre a necessidade de habitação, fator que norteava as ocupações urbanas dos anos 1970 (MOURA, 2017). Essa transição, entretanto, pode ser considerada 
atrasada devido à democratização tardia em Portugal, o que levou seus jovens a importarem modelos de outros países europeus, como Inglaterra, Alemanha e Holanda (LÓPEZ, 2017) - localidades que já apresentavam experiências de okupações - como já citado, os squattings.

Autores como Varela e Alcântara (2016) e Baía (2002) distinguem as ocupações (apesar de inseridas em um contexto anárquico de subversão geral) das okupações dos anos 1990, considerando que aquelas estavam relacionadas à luta popular pelo direito à habitação, devido ao aumento da renda do solo, à ausência de alternativas à propriedade privada e de facilidades para o arrendamento. Já as okupas se valiam - e ainda o fazem - de reivindicações por novas relações que não calcadas na posse e na propriedade privada. De acordo com López (2018), os espaços autônomos das okupas atuam como pontos de apoio às comunidades e, ao contrário das ocupações, servem majoritariamente a um perfil dominante de classe, etnicidade e gênero, refletindo o estereótipo do europeu jovem, branco, politicamente articulado, ativista, artista e militante (LÓPEZ, 2017 apud KADIR, 2014), o que faz com que o caráter político dessa prática social seja, por vezes, questionado (LÓPEZ, 2017).

As okupas sofrem influência dos movimentos cíclicos e das diferentes fases das políticas urbanas e do desenvolvimento urbano. Nesse sentido, o contexto de crise financeira global, de disseminação do neoliberalismo e 
das políticas de austeridade, em meados de 2008, transformou essas insurgências urbanas, anteriormente invisíveis, em indicadores de recessão econômica, especialmente em Portugal e na Espanha (MAYER, 2016).

No levantamento apresentado por Moura (2017) entre 1993, quando surge a Fundação da Casa Reciclada no Porto, e 2017 foram registradas aproximadamente 150 okupas em Portugal. Entretanto, a garantia de direito à propriedade privada, inscrita no artigo 62 da Constituição da República Portuguesa (1976), empoderou as ordens de despejo em um período em que era "praticamente legal ocupar casas devolutas" (MOURA, 2017, s.p.). É importante mencionar, ainda, que o teor negativo atribuído às ocupações no período pós-Constituição Portuguesa e a consequente diminuição de apoio popular ao movimento refletem o alto número de casas abandonadas atualmente frente à quantidade de casas devolutas direcionadas para habitação nos anos 1970 (MOURA, 2017). A própria aprovação do Decreto-Lei 198-A/75, que regularizou a ocupação de edificações devolutas para fins habitacionais, é reflexo dessa diferença, uma vez que admitia que:

Há que resolver os problemas suscitados pelas ocupações que têm vindo a verificar-se de fogos devolutos. (...) em muitos outros casos, porém, importa reconhecer que, embora por via ilegal que se não poderá tolerar no futuro, se trata de actuações inseridas na satisfação de necessidades urgentes e atendíveis de estratos extremamente desfavorecidos da população (PORTUGAL, 1975). 
Nesse sentido, é esperado que as okupas que funcionam por meio do arrendamento da propriedade e sob a liderança de associações constituídas geralmente perdurem mais, uma vez que estão mais protegidas do que aquelas que não se valem de meios legais ou que surgem como forma de retaliação a despejos. Aquele perfil marcou o período de 2002-2012, enquanto este, característico de okupas efêmeras, também conhecidas por okupações flash, marcam os anos posteriores até o presente momento (MOURA, 2017).

\section{Ocupações e okupas no Brasil, um breve apa- nhado}

É impossível pensar o termo ocupação sem relacioná-lo com a longa história de exploração e exclusão presente nas cidades brasileiras. No período da República, em um contexto de regulação urbana e fim da escravidão, as primeiras favelas, originadas no final do século XIX (CAMPOS e LÓPEZ, 2020), surgiram como alternativa de construção próxima a serviços e infraestrutura. Outro período conturbado na história do país ocorreu com a ditadura militar, quando os movimentos sociais por terras urbanas foram repreendidos, tornando-se, ao mesmo tempo, mais fortes e influentes.

O processo de redemocratização do Brasil introduziu a condição de "função social da propriedade" nas bases constituintes, oferecendo um reforço aos movimentos 
sociais de ocupação (PAOLINELLI e CANETTIERI, 2019), ainda que provisoriamente. Por outro aspecto, as ocupações e a noção de participação popular ficaram mais afloradas devido aos trabalhos de base realizados pelo Partido dos Trabalhadores (PT) nos municípios. Foi no ano 2000 que a moradia passou a ser um direito institucional, uma vez adicionada à Constituição, entrando em vigor a garantia do cumprimento da função social de um imóvel como requisito da posse (CAMPOS e LÓPEZ, 2020).

Como escrevem Campos e López (2020, p. 112 - tradução das autoras) "Até o ano de 2001, todos os instrumentos de políticas urbanas que atendiam à Constituição eram formalmente construídos e regulados sob o Estatuto da Cidade, que tinha como base o mote do direito à cidade" Apesar da institucionalização e legitimação jurídica de tais aspectos, a eficácia da lei é questionável, visto que diversos imóveis se encontram sem ocupação nos centros urbanos brasileiros. Entre a série de fatores está a especulação imobiliária, impulsionada pelo poder judiciário, que concede a causa aos proprietários na maioria das vezes. Ainda que não, algumas ocupações são alvos de violência estatal ou privada.

Apesar de o Brasil ter vivido uma onda progressista, a

8. No original "By 2001, all the urban policy instruments called for in the constitution were formally brought together and regulated under the Estatuto da Cidade, having as one of its bases the right to the city." 
tomada de medidas de austeridade em favor da expansão econômica global, a violência policial contra movimentos sociais e contra sujeitos subalternos e os problemas de infraestrutura do programa Minha Casa Minha Vida (MCMV) são alguns apontamentos-chave que confirmam a não-provisão plena dos direitos à cidade por parte daqueles governos (CAMPOS e LÓPEZ, 2020). De forma agravante, presencia-se, ainda, a partir de 2016, uma redução sistemática dos direitos adquiridos. A queda da democracia brasileira, a qual vinha crescendo a pequenos passos, começou com um rápido processo de desmantelamento das instituições que a auxiliavam, de congelamento de gastos sociais, de crescimento das privatizações e demais fatores que, mais uma vez, fortaleciam o status neoliberal do país-empresa. Assim, o questionamento da manutenção de um sistema calcado na propriedade privada tomou conta das okupas no Brasil, uma vez que foi a partir da constatação da precarização da vida dos sujeitos frente ao lucro decorrente do projeto neoliberal que se criaram as alianças de enfrentamento.

No Brasil, o movimento das okupas iniciou-se em Santa Catarina, também na década de 1990, com a influência direta dos anarco-punks (RUDY, 2011). Porém, com a virada do milênio, as circunstâncias política, social e econômica instigaram o surgimento de novas okupas, sendo o tensionamento da precarização mais extremo no ano de 2013. Para Paolinelli e Canettieri (2019, p. 832) "Influen- 
ciados pelas jornadas de julho de 2013 e pelas mobilizações contra os megaeventos, os grupos organizados ligados às ocupações urbanas complexificaram seu repertório de organização e ação política", em um processo descrito como a hibridização das lutas urbanas, alterando o relacionamento dos movimentos sociais com as instituições públicas e privadas. Curioso perceber que a crise de 2008, catalisadora dos movimentos das okupas na Europa, chegou no Brasil cinco anos depois com políticas de austeridade repassadas à população.

Quanto aos termos legais, o artigo 1276 do Código Civil aponta que propriedades ociosas devem ser revertidas ao poder público, garantindo a expropriação do imóvel e a Constituição Brasileira, no artigo 170, caput e incisos II e III, assegura o direito de propriedade àqueles que fizerem valer a função social em vias de garantir uma existência digna (LIMA, 2012). Todavia, como o argumento libertário das okupas se constrói a partir de um projeto que não está atrelado à propriedade privada, a luta pela posse do imóvel ocupado é uma questão crucial. Ainda assim, em sentido mais amplo, a tomada da edificação por uma okupa está para além da moradia; trata-se de um espaço para atividades culturais, para políticas públicas e demais ações que se configuram para além do Estado.

Como conclusão dessa parte, pode-se perceber que a precarização dos modos de viver é generalizada, acometendo Norte e Sul globais, mas os artifícios de combate 
ao neoliberalismo também emergem. Assim, tanto países do Norte quanto do Sul refletem a respeito e inauguram novos espaços de vida a partir dos instrumentos adquiridos com o passar do tempo. Desse modo, seria possível pensar a teoria decolonial e o resgate do comunal relacionados às questões do comum e das okupas no Brasil?

\section{A perspectiva decolonial, outra vertente de ação?}

Diversas contribuições sobre o comum no contexto decolonial brasileiro foram desenvolvidas por parte de docentes e discentes da Universidade Federal de Minas Gerais (UFMG), especialmente das áreas de Arquitetura e Urbanismo, Direito e Geografia. Cruz (2017) apresenta a aproximação entre o comum e o decolonial pelo viés da tradução e aponta o abismo linguístico, uma vez que não existe uma tradição consolidada no Brasil acerca da prática política dissertada nesse texto. Para tanto, a autora traça um caminho experimental de construção desse vocabulário, com as palavras fazer-comum, recursos comuns e comuneiro.

Por outra perspectiva, Tonucci Filho e Costa (2017) aplicam a visão sobre o fazer-comum na cidade ao elaborarem o pensamento de que essas práticas políticas do Sul Global ocorrem em um local de incertezas, mas onde as relações de compartilhamento e solidariedade se sobrepõem 
à precariedade da vida. Adicionam também o fato de que o processo de cercamento nas colônias ocorreu com a captação forçada das terras e recursos que antes eram usados de forma comunal.

Logo, a partir dos apontamentos mencionados, indagase: como relacionar a prática política do comum e das okupas com a teoria decolonial, uma vez que a discussão ascendeu dos países colonizadores? Mayer (2015) apontou um caminho quando escreveu a seguinte reflexão:

\begin{abstract}
Pensando as resistências históricas do povo brasileiro, poderiam elas também serem resgatadas pelo prisma do comum? Seria o grito 'essa terra tem dono!', do guerreiro guarani Sepé Tiaraju contra o saqueio das terras indígenas pelos colonizadores europeus, a heróica resistência dos (as) conselheiristas da cidade de Canudos contra o poder central da nascente República ou a resistência por mais de um século do imbatível quilombo dos Palmares, lutas que podem ser historicamente apreendidas sob o registro do comum? (MAYER, 2015, p. 119).
\end{abstract}

Com o intuito de averiguar inicialmente tal questão, as produções de Mignolo (2009) e Souza (2002) foram consultadas. O primeiro autor alerta para diferenças cruciais entre o comum e o comunal e enfatiza que desconsiderar tais pontos poderia levar a uma perpetuação de formas de violência e de colonialidade. Mignolo (2009) estimula a reflexão sobre o ajuste do mundo por volta de 1500:

As primeiras civilizações a sofrerem as consequências da formação e expansão da civilização do Oeste foram 
as Inca, Asteca e Maia. Uma das consequências foi o desmantelamento do sistema comunal de organização social que algumas nações na Bolívia e Equador hoje lutam para reconstruir e reconfigurar. Pela perspectiva europeia, o comunal pode parecer como o socialismo e o comunismo. Mas não é. Socialismo e comunismo nasceram na Europa como resposta ao liberalismo e o capitalismo. Mas o sistema comunal não (MIGNOLO, 2009, p. 30).

Pode-se sugerir, diante dessa perspectiva, que o comum, precedente ao capitalismo, ressurge atualmente como prática política de enfrentamento ao neoliberalismo, enquanto o comunal combate o ocidentalismo. Assim, o comunal, como integrante do pensamento decolonial, não deveria ser diretamente vinculado ao comum, pois ambos surgem de pilares distintos.

Patzi Paco (2004 apud MIGNOLO, 2009) explica que o termo comunal refere-se a direitos coletivos de uso e administração de recursos, ao mesmo tempo que se refere a direitos de grupos, famílias e indivíduos de gerirem e dividirem os benefícios do que é produzido comumente. A distinção entre empregado/patrão acaba, bem como a noção de propriedade privada. Esse é um projeto que resgata memórias e vivências das comunidades andinas e que se enquadra como uma alternativa ao sistema ocidental-neoliberal, decolonizando o Estado, a educação, a linguagem, a economia e a sociedade. Ou seja, esse é um projeto que resgata do ocidentalismo a imaginação própria de um futuro não-capitalista, cujos pilares são de- 
coloniais.

Reflexões sobre as insurgências urbanas instigaram um paralelo com a teoria decolonial, inserindo o ocidentalismo como problemática prévia aos modos do liberalismo (MIGNOLO, 2009). Esse fato permitiu compreender os efeitos da colonização nos países colonizadores, sob a perspectiva das ações dos comuns urbanos, e nos países colonizados, a partir do comunal indígena de tradição latino-americana (SOUZA, 2002; MIGNOLO, 2009).

A partir disso, o artigo busca responder: como nós, sulamericanos, devemos nos aproximar de políticas da luta anticapitalista que surgem dentro do berço do ocidentalismo? Para as autoras, a prática comum, anticapitalista e anti-neoliberal é essencial, uma vez que a sociedade se encontra inserida nessa circunstância. O importante a ser destacado, ainda, são as diferenças de tratamento que são atribuídas às práticas políticas, validando, portanto, a prática comum ressignificada do contexto europeu a partir de outras leis, de outras construções culturais e de outros tratos econômicos, uma vez que o cotidiano da população brasileira é imbuído nas relações com fundos capitalistas e coloniais. 


\section{Conclusão}

É extremamente importante que esteja clara a distinção entre os objetivos dos movimentos aqui estudados: o comum nasce como um enfrentamento ao cercamento de terras na Idade Média, sendo, portanto, uma prática europeia contra o crescimento de um sistema econômico que nasceu na mesma circunstância. Já a atualização do termo refere-se a práticas que vão contra o neoliberalismo e como uma alternativa à "moeda" da relação público/privado, como é o caso das okupas, questionadoras da propriedade privada, seja ela por parte do Estado ou do mercado. Por outra perspectiva, o comunal denomina uma série de práticas que iam e vão contra o ocidentalismo, dizem respeito aos povos tradicionais que lutavam e lutam contra a hegemonia do modo de vida imposto pelo ocidente, sendo relativo à defesa e à conservação de uma outra episteme.

Ainda assim, o que se pode perceber é uma precarização global gerada pelo neoliberalismo, mesmo que sejam evidentes as diferenças entre os países colonizadores e colonizados. As ações truculentas contra as manifestações de luta por moradia ocorrem historicamente no Brasil, seja pela violência direta ou por demais negligências. O balanço dos movimentos sociais urbanos da década de 2010, feito por Paolinelli e Canettieri (2019), mostra que o desenvolvimento dessas lutas se formou num processo de hibridização, em que os movimentos sociais foram ar- 
ticulando outros arranjos com a sociedade e instituições, a fim de sobreviverem. No caso de Portugal, o aumento das desigualdades se tornou mais perceptível com a crise de 2008 e a entrada massiva de imigrantes provenientes de zonas de conflito. O que se percebe nesse contexto é uma mudança no caráter dos movimentos sociais de luta coletiva pela reivindicação de direitos sociais, políticos e civis, em meados de 1970, para a busca pela manutenção e exercício destes, mais recentemente ligados à crise socioeconômica, à exploração neoliberal e à classe política.

Talvez a maior semelhança entre os movimentos do Sul e do Norte esteja no fator central do combate à precariedade da vida dos sujeitos, uma vez que são imbuídos a construírem práticas do comum, diferentemente do usual de um dia a dia esvaziado de sentido coletivo. Representam modos distintos de viver, experimentar as cidades e, ao misturarem teoria e prática, passam de sujeitos anestesiados a sujeitos desejantes, configurando de fato o espaço para a vida, em um cotidiano baseado em autogestão, cooperação uso comunitário.

\section{Referências}

ASCHOFF, Nicole. The New Prophets of Capital. London: Verso, 2015.

AUGUSTO, Fábio. Movimentos Sociais em Portugal: o an- 
tes e o depois. Ação Pública e Problemas Sociais em Cidades Intermediárias. Lisboa, v. 1, p. 5-27, 2013.

BAÍA, João. Bairro da Relvinha: memórias de resistência. Ler História. A transição democrática portuguesa. Dossier: Interdisciplinaridade em acção. Experiências de pesquisa em contextos rurais. Lisboa, v. 63, p. 179-197, 2012.

BUTLER, Judith. Corpos em aliança e a política das ruas: notas para uma teoria performativa de assembleia. Tradução Fernanda Siqueira Miguens. Rio de Janeiro: Civilização Brasileira, 2018.

CAMINHA, Júlia. O comum como ação coletiva no espaço cotidiano. História, Natureza e Espaço, Rio de Janeiro, v. 7, n. 1, p. 1-14, 2018.

CAMPOS, Clarissa; LÓPEZ, Miguel. Squatting activism in Brazil and Spain: Articulous between the right to housing and the right to the city. In: GRASHOFF, Udo. Comparative Approaches to Informal Housing Around the Globe. London: UCL Press, 2020.

CHAUÍ, Marilena. Democracia e sociedade autoritária. Comunicação \& Informação, Goiânia, v. 15, n. 2, p. 149161, jul./dez. 2012.

CRUZ, Mariana. O novo vocabulário do Comum: ensaio para uma leitura pós-colonial. ANAIS do XVII Encontro Nacional da Associação de Pós-Graduação e Pesquisa 
em Planejamento Urbano e Regional, São Paulo, v. 17, n. 1, 2017.

DARDOT, Pierre; LAVAL, Christian. Comum: ensaio sobre a revolução no século XXI. Boitempo Editorial, 2017.

ENRIGHT, Theresa; ROSSI, Ugo. Ambivalence of the Urban Commons. In: WARD, Kevin. et al. The Routledge Handbook on Spaces of Urban Politics. London: Routledge, 2018.

FEDERICl, Silvia. Calibã e a bruxa. Mulheres, corpo e acumulação primitiva. Rio de Janeiro: Editora Elefante, 2017.

FEDERICl, Silvia. Feminism and the Politics of the Commons in an Era of Primitive Accumulation. In: VAN METER, Kevin; HUGHES, Craig; PEACE, Stevie. Uses of a Whirlwind: Movement, Movements, and Contemporary Radical Currents in the United States. Chico: AK Press, 2010.

FERNANDES, Marcos. Syöpäville, okupa rural e aldeia musical. Cadernos de Arte e Antropologia, $n^{\circ} 2$, p. 115121, 2012.

GASPAR, Carlos. O processo constitucional e a estabilidade do regime. Análise Social. Lisboa, vol. xxv, p. 9-29, 1990.

HARDIN, Garrett. The tragedy of the commons. Science, London, v. 162, n. 3859, p. 1243-1248, Dez. 1968. 
HARDT, Michael; NEGRI, Antonio. Commonwealth. Cambridge: Belknap Press of Harvard University Press, 2009.

LEITÃO, Diogo. Movimento Okupa: uma perspectiva de exclusão social. 2016. Dissertação (Mestrado em Psicologia Forense e da Exclusão Social) - Universidade Lusófona de Humanidades e Tecnologia, Lisboa, 2016.

LIMA, Andressa. "Okupar, insistir e resistir": uma etnografia das práticas de ocupação urbana - Fortaleza/Ceará. 2012. Dissertação (Mestrado em Antropologia Social) - Universidade Federal do Rio Grande do Norte, Natal, 2012.

LÓPEZ, Miguel. Introduction: The politics of Squatting, Time Frames and Socio-Spatial Contexts. In: LÓPEZ, Miguel (ed.). The Urban Politics of Urban Squatters' Movements. New York: Palgrave Macmillan, 2018.

LÓPEZ, Miguel. Squatters and migrants in Madrid: Interactions, contexts and cycles. Urban Studies, California, v. 54, n. 11, p. 2472-2489, 2017.

MAYER, Joviano. O comum no horizonte da metrópole biopolítica. 2015. Dissertação (Mestrado em Arquitetura e Urbanismo) - Universidade Federal de Minas Gerais, Belo Horizonte, 2015.

MAYER, Margit. Neoliberal urbanism and uprisings across Europe. In: MAYER, Margit; THÖRN, Catharina; THÖRN, 
Håkan. Urban Uprisings: Challenging Neoliberal Urbanism in Europe. London: Palgrave Macmillan, 2016.

MIGNOLO, Walter. The communal and the Decolonial. Turbulence, London, n. 5, p. 29-31, 2009.

MOURA, Zita. Okupas: uma história que se escreve a cada dia. In: Jornal Mapa. 2017. Disponível em: <http:// www.jornalmapa.pt/2017/11/07/okupas-uma-historia-escreve-cada-dia/>. Acesso em: 19 de agosto de 2019.

OSTROM, Elinor. Governing the commons: the evolution of institutions for collective action. New York: Cambridge University Press, 1990.

PAOLINELLI, Marina Sanders; CANETTIERI, Thiago. Dez anos de ocupações organizadas em Belo Horizonte: radicalizando a luta pela moradia e articulando ativismos contra o urbanismo neoliberal. Cadernos Metrópole, v. 21, n. 46, p. 831-854, 2019.

\section{PORTUGAL. Constituição da República Portuguesa.}

Lisboa: Presidência da República, [1976]. Disponível em: <https://dre.pt/web/guest/legislacao-consolidada/-/ Ic/337/201701181101/128025/diploma/indice>. Acesso em: 12 de agosto de 2019.

\section{PORTUGAL. Decreto-lei nº 198-A, de 14 de abril de 1975.}

Estabelece normas de regularização da ocupação de fogos devolutos levada a efeito para fins habitacionais em prédios pertencentes a entidades públicas ou privadas. 
Disponível em: <https://dre.tretas.org/dre/111142/decreto-lei-198-A-75-de-14-de-abril>. Acesso em: 12 de agosto de 2019.

RUDY, Cleber. Urbana subversão: a prática squatter no Brasil. $O$ olho da História, Salvador, n. 17, s.p. 2011.

SOUZA, José. O sistema econômico nas sociedades indígenas Guarani pré-coloniais. Horizontes Antropológicos, Porto Alegre, ano 8, n. 18, p. 211-253, dez. 2002

TONUCCI FILHO, João. Comum urbano: a cidade além do público e do privado. 2017. Tese (Doutorado em Geografia) - Universidade Federal de Minas Gerais, Belo Horizonte, 2017.

254 TONUCCI FILHO, João; COSTA, Heloisa. O comum e a metrópole brasileira: além do impasse da reforma urbana? ANAIS do XVII Encontro Nacional da Associação de Pós-Graduação e Pesquisa em Planejamento Urbano e Regional. São Paulo, v. 17, n. 1, 2017.

VARELA, Raquel; ALCÂNTARA, Joana. Conflitos sociais na Revolução Portuguesa (1974-1975). III International Conference Strikes and Social Conflicts: Combined historical approaches to conflict. Barcelona, p. 11091127, 2016. 